\title{
Parenthetical-modal Type of Using Finite Verbs in the Russian
}

\section{Language}

\author{
Victor Vasilievich Shigurov ${ }^{1} \&$ Tatyana Alexeevna Shigurova ${ }^{1}$ \\ ${ }^{1}$ Ogarev Mordovia State University, Russian Federation \\ Correspondence: Victor Vasilievich Shigurov, Bolshevistskaya street, 68, Saransk, 430005, Republic of \\ Mordovia, Russian Federation.
}

Received: October 30, 2014

Accepted: November 27, 2014 Online Published: March 23, 2015

doi:10.5539/ass.v11n8p292

URL: http://dx.doi.org/10.5539/ass.v11n8p292

\begin{abstract}
The objective of the research work is simultaneous studying the process of modalation as a type of stepped transposition of linguistic units from verbs into the inter-part-of-speech semantic-syntactic category of modal verbs. The author carried out a complex analysis of functional modalation of verbs in the first person singular by the example of the word-from I consider, defined semantic prerequisites, syntactic conditions, attributes and stages of its transposition into modal words. The research showed that finite verbs of the type I consider retain a lively semantic connection with the original lexemes in two-member and one-member parenthetical constructions. With the method of opposition and scale of transitivity, it was possible to reveal the syncretism of properties of the verb and modal words in the structure of linguistic units at different stages of their modalation. The results of the research can be used when composing the Russian transposition grammar.
\end{abstract}

Keywords: Russian, grammar, transposition, modalation, verb, modal word, syncretism

\section{Introduction}

One of the issues of current importance in the Russian theoretical grammar is a complex research of transposition processes of linguistic units in the system of parts of speech and inter-part-of-speech categories (substantivisation, adjectivisation, pronominalisation, interjectivation, adverbialisation, etc.) that meet the needs of people to express thoughts and feelings in their interaction and interlacement as laconically and capaciously as possible (see, for example: Miguirin, 1971; Kim, 1978; Babaytseva, 2000; Shigurov, 1993 \& 2003 \& 2009a; Shigurov \& Shigurova, 2014). Foreign linguists (see Bally, 1955; Tesniére, 1988; Kurilovich, 2000; Marchand, 1967 , etc.) examined in their works types of mutual transposition and interaction between parts of speech within the limits of the transposition theory (translations, conversions). Modalation consisting in the transposition of linguistic units from different parts of speech into the inter-category semantic-syntactic category of parenthetical-modal words occupies a special place among these processes. The importance of the research of modalation in dynamic and static aspects results from a high degree of productivity of subjective-modal meanings in the modern Russian language, strengthening of the personality component in the utterance (see Orekhova, 2011, p. 4, etc.). Insufficient examination of the mechanism of functional and functional-semantic transposition of words and word-forms into modal words dictate the necessity to study its linguistic and extralinguistic reasons, semantic and morphological prerequisites, syntactic conditions, attributes (changes in modalates at the level of lexical and grammatical semantics, grammatical categories and paradigms, morpheme structure, phonetic peculiarities, syntagmatic characteristics, etc.), stages of modalation (in standard contexts) and limits of interaction between different parts of speech and inter-part-of-speech categories (predicatives and modal words) in the structure of linguistic units expliciting different stages of this type of transposition.

\section{Methods}

Methods of analyzing stages of transposition of linguistic units in the system of parts of speech and inter-part-of-speech categories of modal words and predicatives is described at great length and approved based on the vast factual material contained in a series of monographic research studies of V. V. Shigurov on the Russian transposition grammar. Some of them are as follows: (1) stages of substantivisation, adjectivisation, adverbialisation, conjunctionalisation of gerundial and participial forms of the verb with negation (Shigurov, 1993); (2) stages of pronominalisation of linguistic units of different part-of-speech assignments (Shigurov, 2003); (3) stages of interjectivation of linguistic units of different parts of speech and concurrent transposition 
processes of verbalization, particulation, etc. (Shigurov, 2009a); (4) stages of predicativisation and concurrent processes of adjectivisation, adverbialisation, modalation, etc. (Shigurov, 2009b). The author has composed a prospect of the modern Russian transposition grammar and worked out a program of studying syncretic linguistic and speech unit in the system of parts of speech and inter-part-of-speech semantic-syntactic categories (predicatives, modal words) with the use of opposition analysis and indexation methods; the author has prepared a series of sections where types of functional and functional-semantic homonyms as well as peripheral and hybridous formations representing different stages of word and word-form transition from one class of words into another are revealed and characterized; described are heterogeneous speech structures that are in the zone of impact (interaction) of 3, 4, 5 parts of speech involved in several transposition processes at the same time where some single dominating type of transposition stands out (e.g. interjectivation) and several concurrent parallel processes (verbalization, predicativisation, pronominalisation, particulation, etc.); compare, for example, a "pure" type of interjectivation of adverbial word-forms like Bye! So long! See you! and "combined" types: a) Now a kiss! (interjectivation, predicativisation, verbalization); b) No more! Enough! (interjectivation, verbalization, pronominalisation); c) Out! Away! (interjectivation, verbalization, particulation); d) Where! Now! Straight on! (interjectivation, particulation); e) (Quietly!) Tss! (Sh!) (interjectivation, verbalisation), etc.; with methods of mathematical material processes, indices of different stages (steps) of part-of-speech transposition of lexical units are counted; types of peripheral and hybridous structures representing different stages of adverbialisation, adjectivisation, substantivisation, prepositionalisation, conjunctivisation of attributive forms of verbs (in the context of negation of actions), pronominalisation, interjectivation and predicativisation of words and word-forms of different parts of speech are described in monographs, textbooks and series of articles; vast factual materials collected: constructions with words of different part-of-speech assignments in introductive function that, to a varying degree, have undergone modalation in the Russian language. There is information about functioning of syncretic, hybridous word-forms generated by different stages (steps) of modalation of nouns, adjectives and adverbs (including in the function of predicatives), pronouns, verbs in finite forms, in forms of infinitive and adverbial participle. The main stages of functional and functional-semantic transposition of linguistic units into modal words used in the meaning of subjective modality in positions of parenthesis and non-divided word-sentences are defined.

\section{Results}

The research of the modalation process and result shows that a considerable layer of parenthetical-modal units in the Russian language form verbs in varying forms of grammatical representation that retain, with rare exception, a lively semantic connection with the original lexemes. These are modal words derived from finite forms of the verbs: I suppose, you know, it seems, it is said, etc. (1), in forms of infinitive to know, to see, to tell the truth, etc. (2); adverbial participle (frankly) speaking, to all appearances, etc. (3) and contracted passive participle, adjectivized in some cases like apparently, it is known, etc. (4) (see also, Bauder, 1982, pp. 125-131; Vasilenko, 1985; Kudryavtseva, 1988; Russian Grammarin Brief, 1989, pp. 229-230; Mukovozova, 2002).

See contexts of their parenthetical-modal usage:

(1) And, I suppose, you are quite aware of this or guess at least (P. Kozhevnikov. Priest); Well, you know, a real European woman! How much she used to torture me, but I still admire her! (I. Muraviyova. The Would-BeNoble); Well, it seems I found tenants for you. Newlyweds, not wild, not seen in drunkenness (V. Astafiyev. A Transient Goose); Those who were able to work began to feel the trees, they say they did not root out the stumps for they did not hinder (V. Grossman. Everything Flows) [the examples are taken from the National Corpus of the Russian Language published at www.ruscorpora.ru];

(2) The war is going on and, apparently will not end for a long time (V. Astafiyev. Overtone); Your society, frankly speaking, began to irk me... (M. Uspensky. Where We Are Not); The thing is exactly in that he has broken his fast... but she is said to have threatened to banish him for a single drop of drinks (L. M. Leonov. Thief);

(3) But frankly speaking at first I did not think of work at all (A. Berseneva. Flight over separation); Now it was however another case: to all appearances the woman had one over the eight (A. Volos. Real Estate); Victor Hugo's shadow, figuratively speaking, was hovering over me when I was writing this leaflet (K. G. Paustovsky. The Story of a Life);

(4) My short interest to her inner life to which I could not penetrate, though Nika herself was in my power apparently resulted from my desire to change, get rid of thoughts continually roaring in my head and having already made a track that they could not escape (V. Pelevin. Nika). Ashkharumova Mashenka will be for Perovskaya, I, therefore, for Kibalchich ... (D. Bykov. Orthography). 
Finite verbs in the form of passive voice coupled with how, what are also subject to transposition into parenthetical-modal words: as the saying goes as the saying has it, etc. (5). Forms of the analytical passive voice can be included in two transposition processes at the level of inter-part-of-speech semantic-syntactic categories at the same time - modalation and predicativisation: no offence meant (6). Compare:

(5) His actions at that period were characterized by prescience, I would even say far sight, so, as the saying goes, he controlled the situation (D. Granin. Bison); The son is, as the saying goes, in keeping with his mother: he was extremely talented what was long remembered in the House (M. Paley. Commemoration).

(6) "A clever man and sly, no offence meant, and Nadenka, I don't know what and why, in a word, they lived," slightly rocking began grandma Nyura (A. Zhitinsky. Staircase).

Among predicative verb forms in parenthetical position, modalates correlative with verbs in the first person singular are distinguished, like I consider, I confess, I know, I hope, I remind, I remember. The literature contains about twenty verbs that can be used in a special, parenthetical-modal function. Some of them are part of set expressions, compare: I tell it directly, I tell you, I don't argue, I don't understand.

Modalation of finite verbs of this type has a purely functional (grammatical) character not being connected with violation of word denotational identity. It means that verbal lexemes like to hopeare characterized by two types of usage: the verbal usage itself (7) and parenthetical-modal (8) (see, for example, The Large Explanatory Dictionary of the Russian Language, 2001, p. 577):

(7) I hope for your straight forwardness and promise to speak frankly (B. Vasliyev. TrueStoriesandTallTales);

(8) Everybody has, I hope, read the novel Twelve Chairs, so I will not discuss it in detail (V. P. Katayev. My Diamond Wreath).

In the example (8) the verb I hope is simply used in the first person singular in the function of a parenthetical-modal word. As V. V. Vinogradov observed, in most cases production of modal words derived from verbs is not connected with the formation of new lexical units in modal meaning (see [Vinogradov 1986: 602]). In A. M. Peshkovsky's opinion, modalates derived from verbs, or "parenthetical words and expressions" (according to the author's terminology), appear as a result of "keeping back" in speech the corresponding two-member parenthetical sentences included in the middle of other sentences without establishing any grammatical connections with them (Peshkovsky, 1938, p. 372):

(9) ... You know, I am glad to everyone (Griboyedov). $\rightarrow$ I am glad, you to know, to everyone.

A. A. Shakhmatov assigned parenthetical words derived from verbs like I see, (I consider to two types of sentences: two-member and one-member definite-personal (see Shakhmatov, 1941, pp. 265-266 \& 271-272). The ground for transformation of a two-member sentence into a parenthetical clause, in A. A. Shakhmatov's opinion, is presence of two principal members in its grammatical stem - subject-pronoun $I$ and predicate, a verb in the first person singular. See his examples:

(10) You, as I see, enthusiast for cigars; And I confess it is my weakness (N.V. Gogol. The Inspector General); You lisp, I know one tooth in your mouth makes you whistle. (I, 3); Imagine the stir it would have created; I believe my eyesight is better. $(\mathrm{V}, 8)$.

Another group of modal words and expressions, according to A. A. Shakhmatov belongs to one-member definite-personal sentences without subjects:

(11) Well, our secretary, I admit, is a master of reading (Kapnist. Slander); Well, I dare tell you, the governor's duty is quite puzzling (N. V. Gogol. The Inspector General, III, 5); But Piotr Ivanovich had already heard of it from your housekeeper, Avdotya, who, I don't know why, had been sent to Filipp Antonovich Pachechuev-(N. V. Gogol. The Inspector General, III, 5).

In V. V. Vinogradov's work (1975, pp. 70-71), which relied on research studies of A. M. Peshkovsky, A. A. Shakhmatov and others, it was proved that in the Russian language, the entire sentences, reduced in meaning, could transform into the category of parenthetical-modal words; compare: confess and I confess in a parenthetical usage:

(12) (a) I wanted to tell him a couple of words, but, I confess, felt shy (N. V. Gogol. Marriage);

(b) I confess it is my weakness (N. V. Gogol. The Inspector General).

Cases of transformation of verbs in the first person singular into parenthetical-modal words are observed by A. Y. Bauderin a special research study of the process of modalation (see Bauder, 1982, pp. 126-127). The author 
associates the derivation of modalates from verbs like I remember, I think, I guess, I tell the truth with the ellipsis of the subject in a two-member sentence: (remember $=>$ I remember).

In works of many researchers, finite verbs in parenthetical positions are interpreted as one of lexico-syntactical devices of expressing the category of subjective modality of the sentence (see, for example: Russian Grammar, 1980, Vol. 2, pp. 229-230; Brief Russian Grammar, 1989, pp. 503-505; Mukovozova, 2002; Orekhova, 2011; Lekant, 2013, pp. 710-711). In this case, different modalates derived from verbs are connected with the expression of an opinion of a speaker who defines his attitude in the phrase evaluating "their message or way of communication, accentuates something, correlates with the addressee, speech circumstances, the source of information, with the listener's attitude to it, expresses confidence or lack of confidence in what he is saying" (Russian Grammar in Brief, 1989, p. 413).

Finite verbs I suppose, I hope, I remind, etc. in the parenthetical-modal usage convey the following subjective-modal meanings:

(13) (a) meanings of persuasiveness, i.e. trustworthiness/untrustworthiness, confidence/lack of confidence, supposition, assumption, ostensibility (see the modal scale of degrees of trustworthiness/untrustworthiness in (Nagorny, 1999); compare types of categorical (I know, I do not doubt(sure), etc.) and problematical trustworthiness (I hope, I think, I presume, I suppose, I believe, etc.): It is very comfortable in Riga now, the guys, no doubt, would have met me merrily (V. Aksyonov. It's High Time, My Friends, It's High Time); The criticism was severe, but I hope quite useful (V. Aksyonov. Secret Passion); It is I think enough for fighting against the hurricane (A. Dorofeyev Ele-fantik);

(b) Meaning of pointing out the source of information that the author of the speech is himself, i.e. the speaker (I think, consider, suppose, know, etc.): The idea was yours. And it was absolutely right, I think (P. Akimov, Pay for Fear); And I must warn: I am an average computer user, but as you have understood these intricacies, then, I suppose, it will not take much time by me (T. Solomatina. Nine Months, or Comedy of Women's Situations);

(c) Meaning of emotive-expressive evaluation of the message (I confess, I tell it straight, etc.): He tried to be closer to me everywhere and I confess I felt something like father to him (V. Rybakov. "Crown Prince"); Their life was, to tell it straight, merry! (S. Osipov. Tempers for Foma);

(d) Meaning of logical evaluation of the utterance that consists in highlighting key points of meaning, pointing out the most important moments with the purpose of drawing attention of the addressee of the speech $(I$ emphasize, etc.) as well as connecting the dots between the message and previous text fragments (I remind, repeat, etc.): In this connection I would like to speak about some young and let me emphasize talented scientists who caught by fashionable concepts thought of themselves as innovators (V. Aksyonov. Ticket to the Starts); We have arun-through today and in a week, I remind you, a concert devoted to elections (A. Pristavkin. Tamara Radio Station);

(e) Meaning of agreement with someone's opinion (I don't argue, I don't object, etc.); compares antonymic parenthetical clauses: who argues; nobody argues (see The Large Explanatory Dictionary of the Russian Language, 2003, p. 1251): I took, but I took Soviet money! I registered for money, I don't argue, it happened. But our secretary Prolezhnev is good too! (M. A. Bulgakov. The Master and Margarita); The words themselves would have come back to my throat in a tato-barazo-gonmen-shecho-khaarushabracadabra, I would have put the glass on the table... and now on put on the film from this shot, from the past to the future, as you please, I don't object, but I would say another phrase, 'Shura, what time is it now?'(A. Volos. Real Estate);

Most modalates derived from verbs of this kind are characterized by semantic syncretism: they combine semes of several meaningful categories in one and the same parenthetical-modal usage. That is why classification of modalates is crisscross by nature. It is not difficult to observe that parenthetical-modal units, like I hope, I think, I consider, I suppose represent two rubrics of classification ( $\mathrm{a}, \mathrm{b}$ - see above), evaluating the reliability of the utterance by indicating its source, i.e. the opinion, attitude of the speaker (see Russian Grammar in Brief, 1989, p. 504).

As for word-forms I confess, I tell it straight, they convey a wide range of emotive evaluations of the utterance: surprise, disappointment, satisfaction, admiration, etc. In the Russian academic grammar, the emotional attitude to the message expressed with the help of the parenthetical-modal component like I confess is qualified as non-differentiated, indefinite (see Russian Grammar, 1980, Vol.. 2, p. 230):

(14) By virtue of service I read the letters of your respectable mother and your notes-not all yet!-and I confess am surprised! How could it happen that you, a sensible person fall into the sphere of action of officers of gendarme administration? (M. Gorky. The Life of Klim Sangin); Fifteen years ago, you taught me. I remember, 
I confess, without special pleasure. Well, I hated teaching, moreover, I did not actually need it, just followed the youthful fashion to earn on one's own. (A. V. Amfiteatrov. Criminal Mob); But I confess I was sorry to learn that you, a Russian man, had to stay in a foreign country... (K. M. Stanyukovich. Adventures of a Sailor); I confess I rested great hopes on you! (K. M. Stanyukovich. Priests);

In case of difficulties or search for an expression, a speaker can use almost empty insertions, like, for example, desemantized verbs in the first person singular like I tell you(see [Russian Grammar 1980, v. 2: 230]):

(15) In rare cases when there was no possibility to get rid of it he used to say moving his bushy grey eyebrows, "Well, man, the story is, I tell you, hm! (D. V. Grigorovich. Short Happiness); There was such a noise, I tell you, enough to try the patience of a saint (F. D. Kryukov. Satellites); An outline map, I tell you, is a wonderful invention when one wants to teach geography to children (A. Rybakov. Heavy Sand).

As opposed to other modalates derived from verbs, word-forms like I confess do not imply such meanings of subjective modality, like, for example, description of an event in terms of duration, degree of commonness of the narrated facts [compare: it happens(16)]; a contact establishing meaning [compare: understand ,you know, imagine, you see(17)]; indication for an indefinite source of information [compare: is said, is reported, is told(18)]; meaning of assumption [compare: let us assume, let us suppose, let us say (19)]. Compare contexts of their parenthetical-modal usage:

(16) But they can make friends, it happens, people make friends united by their dislike for their profession (V. Grossman. Life and Destiny);

(17)You know, I have come here for business. For several days (I. Grekova. Turning Point);

(18) "I say! Sailor on duty,) chief mate called. "In the Barents Sea, they say, the storm is measured 8. We are lucky." (G. Vladimov. Three-minute Silence);

(19) Let us suppose she does not care for father, but mother is no stranger to her! (V. Belousova. The Second Shot);

There are certain semantic constraints on parenthetical-modal type of using verbs in the first person singular. It is mainly typical of verbs with the meanings of speech (I confess, I tell you, I emphasize, I emphasize, I remind, I repeat), evaluation (I don't argue), way of thinking (opinion: I suppose, I consider, I think; belief: I believe; understanding: I see); knowledge (I know); memory (I remember), perception (I feel, I see). At the same time, it is hardly possible to expect using verbs in the first person singular in the function of parenthetical-modal components with the meanings of existence (exist, be, etc.), realisation or happening (occur, happen, come out, etc.), disappearance of something (disappear, continue, finish, etc.), biological existence (live, die, come alive, revive, etc.), spatial location (be situated, be located, live, quarter, etc.), of different types of relationship between phenomena of reality (coincide, differ, etc.), physiological state (sleep, be ill, feel cold, etc.), sound (sound, ring, wheeze, squeak, etc.), movement (move, walk, dance, etc.) and so on (see the semantic classification of the predicate lexicon in (Vasiliyev, 2005)).

Verbs of speech like I remind, I repeat, I emphasize are used in the parenthetical-modal function performatively: the fact of their pronunciation itself at the moment of speech means realization of the action meant. In such cases, there is a neutrality of the aspectual opposition with the actualization of the meaning of the current moment of speech: let me remind/I remind; let me repeat/I repeat; let me accentuate/I accentuate. The performative type of using such speech verbs coupled with neutralization of aspectual opposition creates the right conditions for transposition of their forms of the future tense into semantic sphere of the actual present tense; compare the synonymy of forms: Tomorrow, let me repeat( $\approx$ 'I repeat'), it is necessary to come to work. The same is in the following sentence:

(20) She occupied a responsible position of the principal keeper in the museum, though, let me remind, she had no near-Moscow residence permit, neither had her husband (O. Zayonchkovsky. Happiness is Possible: Novel of Our Time) ( $\approx$ 'I remind').

What draws our attention is a possibility of changing the number by finite verbs in the first person in the parenthetical-modal function, which mainly results from pragmatic factor. What is at issue is in particular the usage of verbs that evaluate reliability of the message by means of indicating the source, i.e. the attitude of the speaker himself (I consider/we consider, I suppose/we suppose and some others). The plural form by indicating one subject is somewhat more correct (less categorical) and that is why is can be preferred in the speech etiquette. Compare:

(21) This kind of approach, I think/we think, does not completely meet the consumers' needs. 
Something similar may be observed in cases of performative parenthetical-modal usage of speech verbs in the first person singular: I emphasize/let us emphasize, I repeat/let us repeat, I remind/let us remind. Compare:

(22) All requirements, let me accentuate/let us accentuate, necessary for realization of the entered engagements, are fulfilled.

It is appropriate to mention Y. D. Apresyan in this connection that the difference between the forms, like I'm asking, I ask, I would like to ask does not consist in meanings of time and mood, but in pragmatics, to be more exact in the degree of politeness: the form of subjunctive mood is the politest form of a request, while the form of perfect aspect is the abruptest (see Apresyan, 1986, p. 215).

At last, it is worth mentioning that transposition of verbs into modal words is stepped by nature, which is seen on the scale of transitivity (A/V(erb) (core of verbs) - $\mathrm{Ab} / \mathrm{V}(\mathrm{erb}) \mathrm{M}(\mathrm{od})$ (verbal periphery) - $\mathrm{ab} / \mathrm{v}(\mathrm{erb}) \mathrm{m}$ (od) (zone of hybridous verbal-modal structures) - $\mathrm{aB} / \mathrm{V}(\mathrm{erb}) \mathrm{M}(\mathrm{od})$ (periphery of modal words) - B/M(od) (core of modal words), fixing the original and final points of movement of varying units from verbs into the category of modal words as well as to the zone of syncretism filled with peripheral and hybridous speech structures, which are characterized by combination of interacting classes of words at a different ratio. Speaking about a "florid" morphological composition of the structural-semantic category of modal words, V. V. Babaytseva points out that in this sphere, there area great many syncretic speech factors that differ in their place on scales of transitivity fixing the connections between modal words and words of notional and functional parts of speech (see Babaytseva, 2000, p. 329). At the same time, some word-forms, adverbs like on the contrary (23a) in particular, can appear in the zone of attraction of three word categories at once: adverbs, conjunctions and modal words (see Isachenko, 1965, p. 274):

(23) (a) He will do everything to the contrary;

(b) He did not fail, on the contrary, he passed the exam perfectly.

Transposition of finite verbs like $I$ consider into the inter-part-of-speech semantic-syntactic category of parenthetical-modal words, as A. A. Shakhmatov mentioned happens in two types of constructions (24) built by the model $\mathrm{N}_{1} \mathrm{~V}_{\text {fm }}$ : (a) in a two-member sentence with the subject expressed by personal pronoun-noun $I$ and (b) in a one-member definite-personal sentence:

(24) (a) This decision I think is wrong;

(b) This decision, think, is wrong.

On this basis, a process of modalation of the word-form I consider can be conditionally presented in several stages or steps on the scale of transitivity reflecting its movement from a verb towards nuclear modal words like just try, probably, it seems, which have lost not only lexical meanings, but also grammatical properties of the original verbs. Compare the functional-semantic type of transposition just try, come here, I dare say into a modal word:

(25) (a) "Come here," I took her outside and said that Slava had a great sorrow and that was why we did not go to festivities (V. Astafiyev. Overtone) (finiteverb);

(b) But Valeria Tikhonovna, I day say, is not alive, if he, so much younger than her, is an old man (I. Grekova. Pheasant) (a modal word derived from a verb).

As for modalation of verbs in the first person singular, as mentioned, it is purely grammatical by nature, it is realized within the limits of original verbal lexemes and is not connected with the formation of new lexical units. That is why the limit of this type of transposition of linguistic units derived from verbs is a stage of periphery of modal words on the scale of transitivity $[\mathrm{aB} / \mathrm{V}(\mathrm{erb}) \mathrm{M}(\mathrm{od})]$. The main stages of modalation of the verbs under study can be illustrated on the example of the word-form I consider, which changes its grammatical status a little as long as it "moves" towards modal words.

The stage of the verb core $[\mathrm{A} / \mathrm{V}(\mathrm{erb})]$ is manifested by contexts of using a typical verb in the first person singular I consider in the position of the predicate of a two-member sentence:

(26)I consider this decision wrong.

The stage of hybridity on the scale of transitivity [ab/v(erb) $\mathrm{m}(\mathrm{od})]$, explicited by contexts of using intermediate verbal-modal structure I consider is divided into two substages: [ab/v(erb) m(od) 1] и [ab/v(erb) m(od) 2].

Substage [ab/v(erb) $\mathrm{m}(\mathrm{od}) 1]$ reflects contexts of using the hybrid I consider in asyndetic composite sentences with explanatory relations between the parts fixed by a colon:

(28) (a) I think: this decision is wrong; 


\section{(b) Think: this decision is wrong.}

Like in (27) case, I consider is a predicate of two-member (a) or main part of one-member predicate unit (b) within the limits of a composite sentence.

Substage (ab/v(erb) $\mathrm{m}(\mathrm{od}) 2$ 2) presents contexts of using the hybrid I consider in a transitive construction, synthesizing attributed of an asyndetic composite sentence and simple sentence with a complicating parenthetical component. Parts of such sentence are divided by a comma:

(29) (a) I think, this decision is wrong;

(b) Think, this decision is wrong.

In such cases, the hybrid I consider combines the properties of the verb and modal word approximately at equal ratio used in the function of a predicate (29a) or main member of the sentence and parenthetical component with the subjective-modal meaning of evaluation of the message by the speaker, from the point of view of problematic trustworthiness (29b). Syncretism covers here, apparently, not only the hybridous, verbal-interjectional form of I consider, but also the syntactic structure in general, which is characterized by properties of both asyndetic composite and simple complicated sentence.

The stage of periphery of words $[\mathrm{aB} / \mathrm{v}(\mathrm{erb}) \mathrm{M}(\mathrm{od})]$ reflect contexts of using modal words functioning within the limits of verbal lexemes. This is the modalate derived from the verb of I consider used in inter- and rarely postposition as a parenthetical component of a simple complicated sentence:

30 (a) This decision I think is wrong;

(b) This decision, think, is wrong/This decision is wrong, I think.

It should be pointed out that in the zone of periphery of modal words as well as at previous stages of modalation, the word-form I consider keeps the main semantic-grammatical characteristic of the verb: part-of-speech meaning of action, predicative form of representation of the verbal lexeme, grammatical categories and forms of aspect (imperfect), voice (active), mood (indicative), tense (present), person (first). Peripheral modalate derived from verb I consider is used in the verbal function of predicate of a two-member construction (30a) or main member of one-member parenthetical construction (30b) included based on a complicating component into the structure of a simple complicated sentence. Functionally, it is similar with other modal words: it expresses subjective-modal meaning characterizing the attitude of the speaker towards the message, in this case the reliability of the narrated information; it serves as a parenthetical component of the utterance getting a special intonation pattern (strengthening, lowering the voice tone, quickening the speech tempo); syntactically it is not connected with the members of the sentence (beyond the parenthetical clause). At the same time, this modalate has no such attributes of nuclear modal words like just try, probably explicating the zone of the core on the scale of transitivity $[\mathrm{B} / \mathrm{M}(\mathrm{od})]$ like absence of lexical meanings and grammatical categories and forms of the original verbs, invariability and total isolation from the verb paradigm (compare: I consider/ we consider). Modalation of the word-forms like I consider does not lead to formation of lexico-grammatical homonyms, it leads to formation of grammatical homonyms functioning within the limits of original verbal lexemes. In fact, these are just two types of using one and the same verbal lexeme I consider in the finite form (31) in ways contexts: (a) the verbal usage itself and (b) the parenthetical-modal usage (in a two-member or one-member construction):

(31) (a) I consider this opinion wrong:

(b) This decision is I think wrong. This decision, think, is wrong.

\section{Conclusion}

The above stated considerations regarding semantic-grammatical aspects of transposition of linguistic units from verbs into inter-part-of-speech category of modal words are sketchy by nature and represent a small fragment of a complex research study of the problem of modalation within the limits of the modern Russian transposition grammar. However, what has been said already proves that word-forms I consider, I suppose in parenthetical-modal usages cannot be adequately interpreted in grammar according to the "either... or" principle, i.e. only as verbs or modal words. In fact, at different stages of modalation, they combine differential attributes of the original and final unit of the part-of-speech transposition at a certain ratio and show different degrees and forms of interaction between the verb and the semantic-syntactic category of modal words. This proves once again that different types of multi-stepped transposition of words and word-forms from one class into another (both single and combined in one lexical unit) represent the phenomenon of the language in action, communication situation (see Stepanov, 2001, p. 31) finally generating grammatical and lexico-grammatical 
homonyms as well as syncretic speech structures that to a varying degree combine properties of several parts of speech at the same time.

\section{Reference}

Apresyan, Y. D. (1986). Performatives in Grammar and Vocabulary (3rd ed., p. 215). Izvestiya of USSR Academy of Sciences.

Babaytseva, V. V. (2000). Phenomena of Transitivity in the Russian Grammar: Monograph. Moscow: Drofa.

Bally, Ch. (1995). General Linguistics and Issues of the French Language. Moscow: Foreign Literature Publishing House.

Bauder, A. Y. (1982). Parts of Speech: Structural-Semantic Classes of Words in the Modern Russian Language. Tallin: Valgus.

Belousov, V. N., Kovtunova, I. I., \& \& Kruchinina, I. N. (1989). Russian Grammar in Brief. Moscow: Russky Yazyk.

Kim, O. M. (1978). Transposition at the Level of Parts of Speech and Phenomenon of Homonymy in the Modern Russian Language. Tashkent: Fan Publishing House.

Kudryavtseva, M. I. (1988). Semantics of Modal Words Derived from Verbs (abstract of scientific paper). Leningrad.

Kurilovich, E. (2000). Essays on Linguistics. Birobidzhan: TRIVIUM.

Kuznetsov, S. A. (2001). The Large Explanatory Dictionary of the Russian Language. St. Peterburg: Norint.

Lekant, P. A. (2013). Syntax. Modern Russian Literary Language. Moscow: ASTPRESSKNIGA.

Marchand, H. (1967). Expansion, transposition and derivation (p. 1). La Linguistigue.

Miguirin, V. N. (1971). Essays on the Theory of Process of Transitivity. Beltsy.

Mukovozova, T. I. (2002). Grammar Status of Modal Words (abstract of scientific paper). Moscow.

Nagorny, I. A. (1999). Expression of Predicativity in Sentences with Modal-Persuasive Particle.

Orekhova, E. N. (2011). Subjective Modality of the Utterance: Form, Semantics, Functions (abstract of scientific paper).

Peshkovsky, A. M. (1938). Russian Syntax in Scientific Coverage. Moscow: Uchpedguiz.

Russian Grammar (Vol. 2). (1980). Moscow.

Shakhmatov, A. A. (1941). Russian Syntax (2nd ed.). Leningrad: Uchpedguiz.

Shigurov, V. V. (1993). Typology of Usage of Attributive Forms of the Russian Verb under the Conditions of Negation of Action. Saransk.

Shigurov, V. V. (2003). Pronominalisation as a Type of Stepped Transposition of Word-Forms in the System of Parts of Speech. Saransk: Mordovia University Publishing House.

Shigurov, V. V. (2009a). Interjectivisation as a Type of Stepped Transposition of Linguistic Units in the System of Parts of Speech. Moscow: Academia.

Shigurov, V. V. (2009b). Predicativisation of Adjectives and Adverbs in the Russian Language: Essence, Stages, Limits. Novosibirsk: ZRNS.

Shigurov, V. V., \& Shigurova, T. A. (2014). On Some Principles of Description of Transposition and Syncretism in the Theory of Parts of Speech. Moscow.

Stepanov, Y. S. (2001). Methods and Principles of Modern Linguistics (2nd ed.). Moscow: Editorial URSS.

Tesnière, L. (1988). Fundamentals of Structural Syntax. Moscow: Progress.

Vasilenko, L. I. (1985). Structural-semantic Role of Modal Words in Text (abstract of scientific paper). Minsk.

Vasiliyev, L. M. (2005). Systematic Semantic Dictionary of the Russian Language. Predicate Lexicon. Ufa: Guilem.

Vinogradov, V. V. (1975). On the Category of Modality and Modal Words in the Russian Language. Moscow.

Vinogradov, V. V. (1986). The Russian Language: Grammar Doctrine on Word. Moscow: Vysshaya Shkola.

\section{Copyrights}

Copyright for this article is retained by the author(s), with first publication rights granted to the journal.

This is an open-access article distributed under the terms and conditions of the Creative Commons Attribution license (http://creativecommons.org/licenses/by/3.0/). 